\title{
Development of Wireless and Portable a Self Learning Braille Device Based on Android Smartphone
}

\author{
Musfiq Amrulloh ${ }^{1}$, Ahmad Fauzi ${ }^{2}$, Kunthi Ratna Kawuri ${ }^{3}$ \\ \{amrulloh.musfiq@student.uns.ac.id ${ }^{1}$, fauziuns@gmail.com ${ }^{2}$, ratnasakura4@gmail.com ${ }^{3}$ \} \\ Sebelas Maret University, J1. Ir. Sutami No.36A, Jebres, Kota Surakarta, Jawa Tengah $57126^{123}$
}

\begin{abstract}
Braille is an essential system for visually impairment people as a source of learning and obtaining information. The process of learning braille is still very dependent on the teacher. Our project aims at developing a self-learning braille device which can help students with visual impairment in learning the system of writing braille letters independently, without reliance on companion teachers. This system uses six small dc solenoids as linear actuators for tactile displays that are used to form a single braille display cell. The dc solenoids and other hardware components are controlled using Atmega328p microcontroller with Arduino Nano platform. To provide the wireless connection between the braille learning device and the android smartphone, we use Bluetooth technology. The solution is designed with a cheap, portable device, user friendly, and allows a blind student to learn braille independently without the help of a teacher.
\end{abstract}

Keywords: braille, self-learning, android, wireless, microcontroller.

\section{Introduction}

Blind people is a term used to describe the condition of a visually impairment people. Visually impairment can lead to limitations for the person, one of which is the limitations in obtaining information. A blind person obtains information using the non-visual senses that can still function one of them is the sense of touch. In the world of education has provided a special service for students with visual impairment with the use of Braille letters used as a medium of reading and writing. To master Braille letters, students need mastery of letter identification techniques, directional control, row tracing and good sense sensitivity. In sharpening the ability is required intensive training and learning by teachers, supported by methods and good learning media. In other words, the learning process of blind students is very dependent on the teacher. Therefore, it takes brilliant solution that can help blind students in studying the system of writing braille letters independently, without dependence on teacher's escort.

Early research about self-learning braille device has been developed using Beaglebone Black processor and an internal speaker in the device [1]. It used the processor as the central part of the kit that controls every component in the device. Other researcher introducing a wireless Body-Braille device and a self-learning system using Xbee module [2]. The size of the device was relatively large and not portable yet. Other researcher has been made the talking SMS braille keyboard to assist the visual impaired users in text messaging [3].

ICCSET 2018, October 25-26, Kudus, Indonesia

Copyright () 2018 EAI

DOI 10.4108/eai.24-10-2018.2280497 
In this paper, we present wireless and portable a self-learning braille device based on android smartphone that can be used to help the visual impairment or the blind for learning the braille character.

\section{System Design}

The system is design to perform all decided the tasks which contain of hardware and software system. The hardware system includes braille learning device (consist of six dc solenoids, microcontroller, relay, push button, Bluetooth module) and a smartphone with android as its operating system. The software system consists of an android application for interfacing the hardware device and Arduino IDE for programming the microcontroller. Both systems are the main-core for developing wireless and portable a self-learning braille device.

\subsection{Hardware System}

This system uses six small dc solenoids as linier actuator for tactile display that used to shape one of braille display cell. Each dc solenoid was joint with small plastic ball. Solenoid is chosen for tactile display because it has a cheaper prize and it's simplicity in use. Solenoid that used in this device DC solenoid with $13 \mathrm{~mm} 13 \mathrm{~mm} 14 \mathrm{~mm}$ dimension and operating voltage $5 \mathrm{v}$ (Fig. 1). The other component that be used for tactile display are piezoelectric ultrasonic linear motor [4], high density magnetic flux [5], electromagnetic linier actuator with inner and outer stators and one moving winding [6].

In this system, the dc solenoids and other hardware components are controlled using Atmega328p microcontroller with Arduino Nano platform as its minimum system for programming the microcontroller. Board platform Arduino Nano is chosen because it has a smaller size than the other Arduino board. It has 6 analog input pins and 14 digital I/O pins. To provide the wireless connection between the braille learning device and the android smartphone we use Bluetooth technology. Bluetooth is a shortrange wireless technology that operates in the $2.4 \mathrm{GHz}$ band [7]. In this work we use smartphone's internal Bluetooth facility and a HC-05 Bluetooth module. More detail about hardware specification that used in this project see Table 1 . 
Table 1. Hardware Specification.

\begin{tabular}{|c|c|}
\hline Hardware Components & Specification \\
\hline Dc Solenoid & $\begin{array}{l}\text { Operating Voltage : } 5 \mathrm{~V} \text { DC } \\
\text { Dimension : } 13 \times 13 \times 14 \mathrm{~mm}\end{array}$ \\
\hline Microcontroller & $\begin{array}{l}\text { Arduino Nano platform } \\
\text { ATmega328p } \\
\text { USB connection } \\
6 \text { analog input pins } \\
14 \text { digital I/O pins (provide } 6 \text { pins as PWM output) } \\
\text { Operating Voltage }: 4.5-9 \text { V DC }\end{array}$ \\
\hline Relay & $\begin{array}{l}\text { Trigger/Coil : } 5 \mathrm{v} \text { DC } \\
\text { NO/NC : 220v } 3 \mathrm{~A} \\
\text { Dimension }: 15 \times 10 \times 11 \mathrm{~mm} \\
\text { Insulation Resistance : } 100 \mathrm{M} 500 \mathrm{VDC} \\
\text { Terminal Type : PCB }\end{array}$ \\
\hline Push Button & Dimension : 6x6x3,1 mm \\
\hline Bluetooth Module & $\begin{array}{l}\text { Module type : HC- } 05 \\
\text { Operating Voltage : } 1,8 \text { to } 5 \mathrm{~V} \text { DC } \\
\text { UART interface } \\
\text { Master and Slave module } \\
\text { RX/TX Communication } \\
\text { Up to +4dBm RF transmit power } \\
\text { Integrated antenna }\end{array}$ \\
\hline
\end{tabular}

The system level block diagram of the hardware system is as follows:

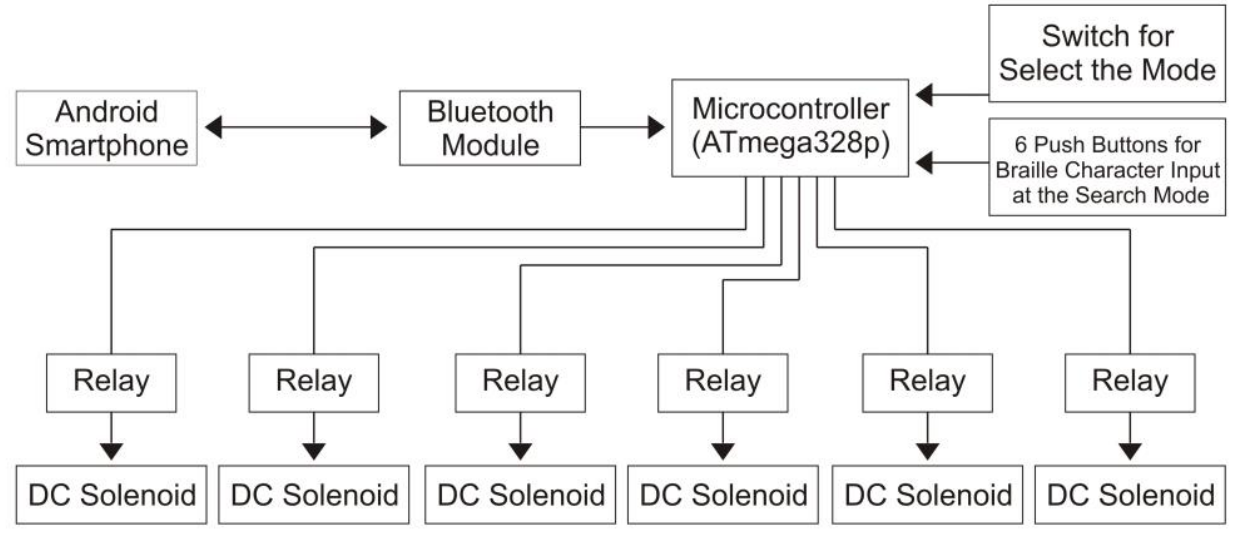

Fig. 1. Hardware System Block Diagram.

The overall hardware system of the braille learning device will have to be powered up with 5V DC (came from 9V battery).

\subsection{Software System}


The android application for interfacing the hardware system was constructed using App Inventor for Android (AIA). App inventor is a visual language programming platform for developing android application. The interface of the App Inventor was used block-based interface so it is a relatively easy for build android application by dragging and dropping the block programming [8]. Besides of that the software system also uses Arduino IDE for programming the microcontroller. Both of them are free open access software.

\subsection{Operating Principle}

The braille learning device in this project was design in order to perform two modes; there are Display Mode and Search Mode. Another work in similar project but not wireless yet was make the device in three modes [1].

1. Display Mode

At the Display Mode, the device is popped out the braille character and then the android smartphone give voice feedback of the character. Figure 2. shows the visualization of the Display Mode.
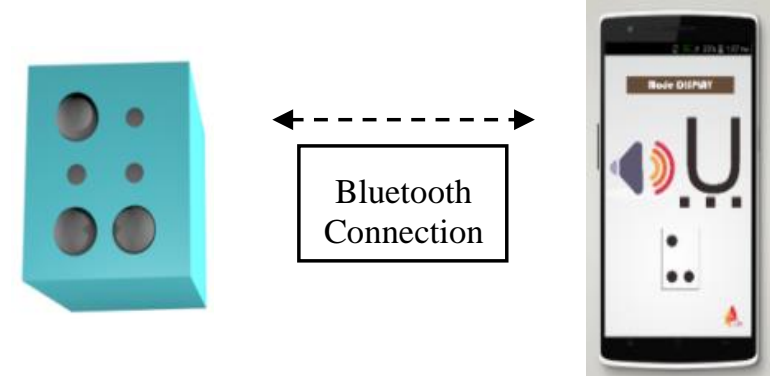

Fig. 2. Display mode of device.

2. Search Mode

At the Search Mode, when some push buttons at the device has been pushed then at the same time the smartphone also will give voice feedback about the braille character. Figure 3. shows the visualization of the Search Mode.

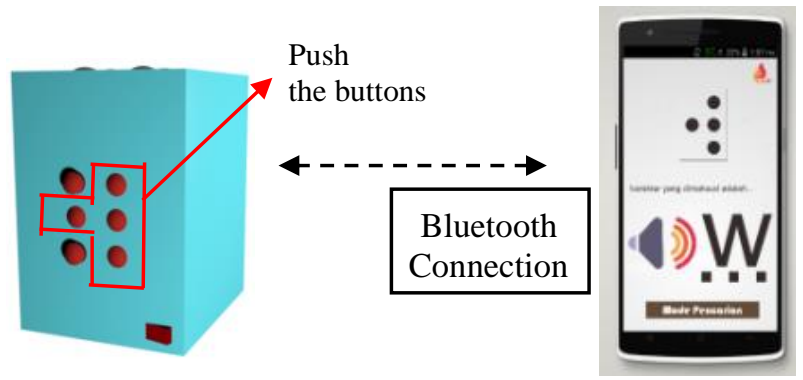

Fig. 3. Search mode of device. 


\section{Result and Discussion}

The result of this project is a wireless and portable device for learning braille that can be operated with or without a teacher. The device is wirelessly connected with an android smartphone via Bluetooth connection. The function of the android smartphone is to give voice feedback about the braille character which is popped out by the device, it done by six dc solenoids that controlled by ATmega328p microcontroller on Display Mode. Be sides that, on Search Mode when some push buttons at the device has been pushed then at the same time the smartphone also will give voice feedback about the braille character. To choice the mode (Display Mode or Search Mode) user can just push the mode switch button at the corner of the device. The body of the device was made using acrylic sheet that catted using laser cutting method. Figure 4. shows the inner part of the device at the making process and Figure 5. shows the picture of the device that has been made.

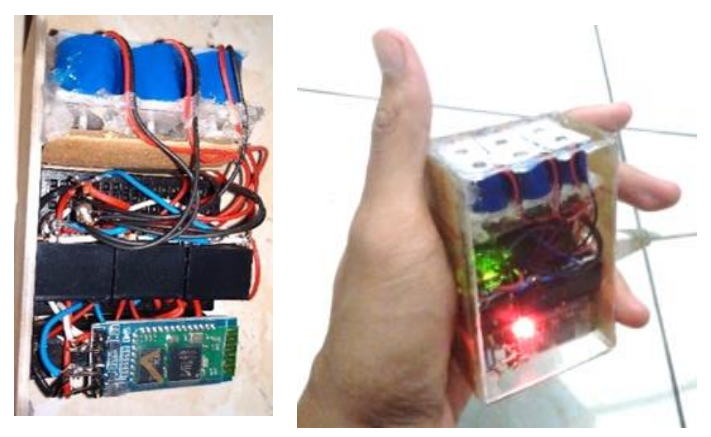

Fig. 4. The inner part of the device.
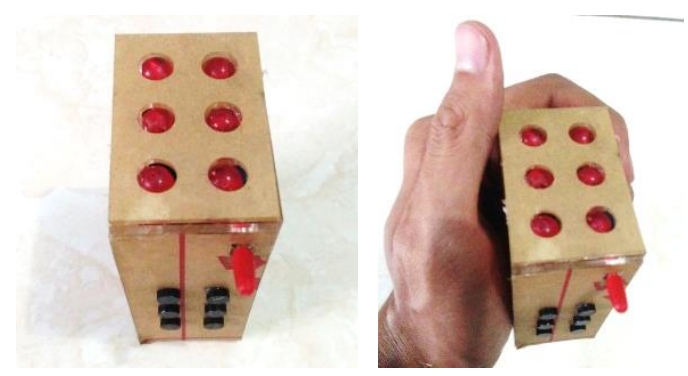

Fig. 5. Wireless and portable a self-learning braille device.

This device has been tested by blind people that understand the pattern of the braille character. They said that every braille character which is popped up and the voice feedback was $100 \%$ correct according to standard braille pattern. And they give the suggestion to make the actuator smaller according to standard braille character size which is every dots are spaced 2,55 mm apart and capable of shaping vertical strokes of 0,7 $\mathrm{mm}$ [4]. 


\section{Conclusion}

This paper presented the development of wireless and portable a self-learning braille device based on android smartphone that was done. The function of the android smartphone is to give voice feedback about the braille character which is popped out by the device. Result shows that this wireless and portable device for learning braille can be operated with or without a teacher. The braille character and the voice feedback was $100 \%$ correct acording to standart Braille pattern. In other word, this device can be used by visually impairment people for learning the braille system independently.

\section{References}

[1] S. Telavane and V. Yadav, "E-Braille-A Self-learning Braille Device," 2016.

[2] S. Ohtsuka, T. Tomizawa, S. Hasegawa, N. Sasaki, and T. Harakawa, "Introduction of a Wireless Body-Braille Device and a Self-learning System," pp. 407-409, 2013.

[3] R. Hamzah, M. Izzat, and M. Fadzil, "Voice4Blind : The Talking Braille Keyboard to Assist the Visual Impaired Users in Text Messaging,” pp. 265-270, 2016.

[4] H. Hern, "Characterization of a Piezoelectric Ultrasonic Linear Motor for Braille Displays," vol. 402, pp. 1-6, 2009.

[5] T. Noguchi, S. Masuyama, and A. Kawamura, "A Novel Small Linear Actuator for Tactile Display Using High Density Magnetic Flux,” pp. 5-9.

[6] S. Masuyama and A. Kawamura, "A novel electromagnetic linear actuator with inner and outer stators and one moving winding for tactile display," in 2016 IEEE International Conference on Industrial Technology (ICIT), 2016, pp. 628-633.

[7] A. Aisha et al., "Jurnal Teknologi Bluetooth-Based Home Automation System Using an Android Phone," vol. 3, pp. 57-61, 2014.

[8] H. J. Kim and J. Modell, "Mobile App Design Tool for Smartphones : A Tutorial," no. 3, pp. 237-243, 2012. 